\title{
TRABALHO E TRABALHO DOCENTE: A PERCEPÇÃO DE DOCENTES DA ÁREA DE FORMAÇÃO GERAL
}

\author{
K. K. O. DA SILVA*, K. DA S. QUEIROZ E S. M. D. MEDEIROS \\ Instituto Federal de Educação, Ciência e Tecnologia do Rio Grande de Norte \\ karlaoliv.ep@gmail.com, karlasqueiroz@gmail.com e soniadanta@gmail.com
}

Artigo submetido em março/2017 e aceito em maio/2017

DOI: $10.15628 /$ rbept.2017.5785

\section{RESUMO}

O presente artigo representa um extrato de uma pesquisa, intitulada Licenciados, bacharéis e a formação para atuar na Educação Profissional Tecnológica, desenvolvida no Programa de Pós-Graduação em Educação Profissional (PPGEP), do Instituto Federal de Educação, Ciência e Tecnologia do Rio Grande do Norte (IFRN). Objetivamos neste trabalho analisar a percepção acerca do conceito de trabalho e trabalho docente de professores que lecionam disciplinas de formação geral em três instituições privadas de ensino profissional do município de Natal. O aporte teórico está abalizado nas concepções de ANTUNES(2008); BRAVERMAN (2011); FRIGOTTO(2012); LIBÂNEO(2001); MARX(1996);
MÉSZÁROS (2005); MOURA (2014); PEREIRA(2004); dentre outros. A metodologia adotada para a coleta dos dados foi a entrevista estruturada e a leitura dos dados foi realizada tendo como referencial a análise de conteúdo ancorada na visão de BARDIN (2011). Como resultados parciais, observou-se que os docentes pesquisados dispõem de conhecimentos sobre trabalho e trabalho docente, tendo em vista que identificam diferenças entre ambos. Porém, é relevante mencionar que essa visão não se baseia na criticidade que há nessa divisão entre os dois tipos de trabalho, quando esse aspecto seria relevante para a sua prática profissional.

PALAVRAS-CHAVE: Trabalho, Trabalho docente, Educação Profissional.

\section{LABOR AND TEACHER'S LABOR: THE PERCECPTION OF TEACHERS OF THE GENERAL FORMATION AREA}

\begin{abstract}
This article brings part of a research developed on the Post graduation Program in Professional Education (PPGEP) in the Institute of Education, Science and Technology of Rio Grande do Norte (IFRN). The research was entitled Graduated, bachelors and the needed formation to work on the Professional Education. The main objective presented here is to analyze the perception about the concept of labor and teacher's labor among those who teach propaedeutic programs in three private professional education institutions in Natal/RN. The theoretical support lays on the
\end{abstract}

conceptions developed by Antunes (2008); Braverman (2011); Frigotto (2012); Libâneo (2001); Marx(1996); Mészaros (2005); Moura(2014); Pereira(2004) among other. The adopted methodology to collect and to analyze data was the half structured interview and the content analysis proposed by Bardin(2011). As partial results, it was noticed that teachers understand labor and teacher's labor as distinctive concepts, but they do not base themselves on a critical point of view, though this perspective should be present and relevant to their professional practice.

KEYWORDS: Labor, Teacher's Labor, Professional Education. 


\section{INTRODUÇÃO}

Embora o trabalho docente possa ser enquadrado, no bojo das relações capitalistas de produção, enquanto força de trabalho que é submetida ao processo de produção de valor, assim como os demais tipos de trabalho que, ao vender sua mão de obra gera valor de uso a ser apropriado pelo capital, os trabalhadores da educação assumem uma peculiaridade, ao passo que contribuindo para o desenvolvimento de uma formação crítica e consciente são capazes de promover a mudança dessa realidade.

Dessa forma, o trabalho docente não se encerra na formação apenas voltada para o desenvolvimento das capacidades técnicas dos sujeitos, o professor tem ainda a possibilidade de adentrar no campo da criticidade e oferecer as condições para que os sujeitos sejam capazes de fazer a leitura das relações sociais e econômicas dominantes, para com compromisso éticopolítico, intervir objetivando sua superação.

Entretanto, para exercer suas atividades profissionais nessa perspectiva, não se pode deixar de pensar na formação do agente dessa atividade. Dessa maneira, o artigo ora apresentado, surgiu de uma pesquisa realizada no âmbito da disciplina "Formação docente para a Educação Profissional" do Programa de Pós-Graduação em Educação Profissional (PPGEP), do Instituto Federal de Educação, Ciência e Tecnologia do Rio Grande do Norte - IFRN, e objetiva analisar a percepção acerca do conceito de trabalho e trabalho docente de professores que lecionam disciplinas de formação geral em três instituições privadas de ensino profissional do município de Natal.

No primeiro momento serão abordados aspectos conceituais sobre o trabalho e o trabalho docente, apresentando as discussões e conceitos sobre a temática, fundamentados nas concepções de Antunes 2008; Braverman 1987; Libâneo 2001 e Marx 1996; seguido do detalhamento metodológico da pesquisa e, por fim, da apresentação dos dados coletados, da análise e dos resultados encontrados nessa etapa desse estudo.

\section{CONCEITUANDO TRABALHO E TRABALHO DOCENTE}

Em sentido elementar, o conceito de trabalho pode ser considerado uma atividade que altera o estado natural das coisas. Com base nesse pressuposto, é possível afirmar que a atividade humana, ao atuar sobre a natureza modificando-a para alcançar a satisfação das suas necessidades, de modo planejado, torna o trabalho uma atividade exclusivamente característica da espécie humana.

De acordo com Marx (1996, p. 211):

[...] O trabalho é um processo de que participam o homem e a natureza, processo em que o ser humano, com sua própria ação, impulsiona, regula e controla seu intercâmbio material com a natureza. Defronta-se com a natureza como uma de suas forças. Põe em movimento as forças naturais de seu corpo braços e pernas, cabeça e mãos -, a fim de apropriar-se dos recursos da 
natureza, imprimindo-lhe forma útil à vida humana. Atuando assim sobre a natureza e modificando-a, ao mesmo tempo modifica sua própria natureza.

Dessa forma, o trabalho não deve ser considerado apenas exclusividade do homem, mas também, enquanto atividade vital para sua sobrevivência, necessidade para manutenção da sua própria existência, natural e eterna, sendo um processo em que altera a natureza ao passo que também modifica o agente da ação.

Aprofundando a discussão acerca da categoria trabalho, identificamos que este apresenta duas perspectivas de análise distintas: uma que nos direciona para uma concepção ontológica do trabalho e outra que aponta para uma concepção histórica.

A perspectiva ontológica compreende o trabalho como um instrumento de mediação entre o homem e a natureza, submetido ao critério de racionalidade. Retomando Marx, em $O$ capital (2014), o autor faz uma interessante analogia com a passagem do pior arquiteto e da melhor abelha. Ressalta que o diferencial do trabalho humano, em detrimento da atividade instintiva animal, é exatamente o fato dele promover a modificação da natureza, submetido a algo anteriormente idealizado, projetado no imaginário, de modo que seus esforços e atenção estão voltados para a realização de ações condicionadas a um fim planejado.

Marx e Engels (1999, p. 27) destacam que:

Pode-se distinguir os homens dos animais pela consciência, pela religião ou por tudo o que se queira. Mas eles próprios começam a se diferenciar dos animais tão logo começam a produzir seus próprios meios de vida, passo este que é condicionado por sua organização corporal. Produzindo seus meios de vida, os homens produzem indiretamente sua própria vida material. [...] O primeiro ato histórico destes indivíduos, pelo qual se distinguem dos animais, não é o fato de pensar, mas o de produzir seus meios de vida (Grifo do autor).

Nas palavras de Braverman (1987, p. 53), o trabalho que ultrapassa a mera atividade instintiva é assim a força que criou a espécie humana e a força pela qual a humanidade criou o mundo como o conhecemos. Para ele, a atividade humana é proposital, guiada pela capacidade intelectual, produto do homem.

A perspectiva histórica do trabalho compreende um olhar sobre as concepções e transformações que este apresenta em cada tipo de sociedade ao longo dos anos. 0 desenvolvimento da produção material dos indivíduos é submetido ao desenvolvimento da divisão do trabalho. Esta, por sua vez, representa as diferentes formas de propriedade, tipos de sociedade. Dito de outra forma, cada divisão do trabalho define novas relações entre os indivíduos no que tange aos três elementos componentes do trabalho estabelecidos por Marx (1996), a saber: a atividade que é o próprio trabalho; a matéria, objeto do trabalho; e por fim os meios ou instrumentos de trabalho.

Com base nesse pressuposto, Marx e Engels determinam os três primeiros tipos de propriedade, a tribal, a comunal e a feudal. A tribal, primeira forma de propriedade, era caracterizada pela inexistência de desenvolvimento da produção e elementar divisão do trabalho. Sua forma de organização para satisfação das necessidades básicas era centrada na família. Na 
propriedade comunal a propriedade é coletiva, os cidadãos tornam-se donos dos escravos e sobre este último recai a responsabilidade pela produção, caracterizando de modo mais marcante o trabalho escravo. Na propriedade feudal, as terras passam ao controle dos senhores e os camponeses assumem a condição de classe produtora, ao passo que também surgem artesãos e comerciantes. Era clara a estrutura estamental da época: no campo, a nobreza, o clero e os camponeses e nas cidades, mestres, oficiais, aprendizes e a plebe de trabalhadores assalariados.

Vencidas as etapas descritas, chegamos à sociedade das relações capitalistas. De acordo com Braverman (1987), o modo de produção capitalista tem como características as relações, as mercadorias, o dinheiro e a compra e venda da força de trabalho. Para tanto, três premissas básicas são estabelecidas: a separação dos trabalhadores dos meios de produção, a condição de trabalhadores livres e venda da força de trabalho.

O empregador, proprietário dos meios de produção e do capital, compra a mão de obra do trabalhador, que por não dispor de outra possibilidade de ganhar a vida, vende sua força de trabalho ao capitalista, em troca de um salário, oferecendo assim as condições para que o empregador expanda seu capital e adquira mais lucro. Dessa forma, o que o trabalhador vende e - capitalista compra é "a força para trabalhar por um período de tempo contratado (BRAVERMAN, 1987, p. 56).

Para Antunes (2008), a força de trabalho transforma-se em mercadoria, e esta por sua vez, tem como objetivo produzir novas mercadorias e gerar mais capital. Quando esse trabalho ultrapassa ao equivalente do pagamento dos seus meios de subsistência, é considerado então trabalho excedente, apropriado pelo capital. O processo de trabalho é assim de domínio dos capitalistas.

Dessa forma, Antunes (2008, p. 3 e 4) complementa:

[...] se por um lado, podemos considerar o trabalho como um momento fundante da vida humana, ponto de partida no processo de humanização, por outro lado, a sociedade capitalista o transformou em trabalho assalariado, alienado, fetichizado. [...] com o advento do capitalismo, houve uma transformação essencial que alterou e complexificou o trabalho humano. Essa dupla dimensão presente no processo de trabalho que, ao mesmo tempo cria e subordina, emancipa e aliena, humaniza e degrada, oferece autonomia, mas gera sujeição, libera e escraviza.

Considerado o trabalho enquanto ação humana que metamorfoseia-se em dados contextos históricos e sociais, o trabalho realizado pelo trabalhador que vende sua força de trabalho na atividade de lecionar, apresenta algumas características que lhe são típicas desse espaço profissional específico.

Vejamos como Libâneo conceitua o trabalho docente (Educar, 2001, p.9):

[...] o trabalho docente é pedagógico porque é uma atividade intencional, implicando uma direção (embora nem todo trabalho pedagógico seja trabalho docente). O que significa dizer que todo ensino supõe uma "pedagogização", isto 
é, supõe uma direção pedagógica (intencional, consciente, organizada), de modo a converter as bases da ciência em matéria de ensino.

De modo que, na concepção do autor, o que caracteriza o trabalho docente é a exigência da intencionalidade, que de acordo com as concepções políticas, culturais, sociais e ideológicas dos docentes poderá desenvolver - ou não - nos sujeitos cognoscentes atitudes de liberdade e autonomia. Contudo, percebemos que alguns profissionais exercem a docência sem formação para "ensinar a ensinar" por não ter os conhecimentos filosóficos, históricos sociais e didáticos, o que dificulta o desenvolvimento de uma prática pedagógica para atender as especificidades de uma formação integral, tendo como eixo central o homem. Essa situação é mais agravante quando se trata dos bacharéis, os quais sempre ingressam na educação por falta de opção, por não conseguirem desenvolver suas atividades profissionais nas empresas.

Como assevera Pereira (2004, p. 05).

A dificuldade reside no fato de que "ninguém promove o desenvolvimento daquilo que não teve oportunidade de construir em si mesmo. Ninguém promove a aprendizagem de conteúdos que não domina nem a construção de significados que não possui, ou a autonomia que não teve a oportunidade de construir" (Destaque do autor).

Portanto, a prática pedagógica desenvolvida por esses profissionais é especificamente na perspectiva de formar intelectuais/trabalhadores, para atender as exigências abancadas pela globalização da economia e pela reorganização da produtividade. Ou seja, uma educação verticalizada, "bancária, acrítica" (FREIRE,1974[2007]). Nesse sentido, é notável que as ações pedagógicas estão intrinsicamente atreladas à formação docente.

Segundo Kuenzer (2011 apud, MOURA, 2014, p.35):

Outra especificidade importante do trabalho docente é o fato de que apesar de ser produtivo, ocorrendo em meio às relações capitalistas de compra e venda da força de trabalho, esse trabalho não é material, pois nele não se separa o trabalhador do produto do seu trabalho.

Dessa forma, o trabalhador tem uma certa autonomia sobre o conteúdo trabalhado. Sabemos, entretanto, que se tratando de uma educação pautada pelos princípios hegemônicos da sociedade capitalista, isso torna-se difícil, a priori no setor privado quando se tem alunos excedentes em sala de aula e um currículo já determinado para atender as demandas do mercado trabalho.

Contudo, faz-se necessário ( $\mathrm{re}$ ) pensar a educação, em que pese o fazer pedagógico em sala de aula, tendo como pressuposto uma concepção de educação emancipatória, omnilateral e contra-hegemônica que possibilite a travessia para uma sociedade fundamentada no princípio de inclusão dos sujeitos e, sobretudo, objetive promover uma educação "para além do capital" (MÉSZÁROS, 2005).

Nesse contexto, percebe-se a premente necessidade do docente navegar nesse espaço dialético e contraditório que permeia a escola e desenvolver ações pedagógicas para além da competência técnica. Portanto, uma proposta educacional abancada nos princípios da cidadania, 
tendo trabalho, ciência, cultura e tecnologia como eixo estruturante para uma base comum, ou seja, que a competência técnica possa dialogar com a formação de um sujeito crítico, capaz de atuar na sociedade em que vive na perspectiva de superação dessa relação de poder predominante no sistema capitalista.

\section{CAMINHOS DA PESQUISA}

As discussões que serão aqui apresentadas compõem os resultados de um projeto de pesquisa em andamento, intitulado Licenciados, bacharéis e a formação docente para atuar na Educação Profissional Tecnológica, vinculada à disciplina de Formação Docente e Práticas Pedagógicas para a Educação Profissional, do Programa de Pós-Graduação em Educação Profissional (PPGEP) do Instituto Federal de Educação, Ciência e Tecnologia do Rio Grande do Norte - IFRN.

Essa etapa da pesquisa consiste em analisar a percepção de docentes que lecionam disciplinas de formação geral e de formação específica, em três diferentes cursos profissionalizantes de duas instituições privadas com relação a três categorias de análise, a saber: percurso formativo, percepção de trabalho e trabalho docente e relação teoria e prática na atuação docente. A pesquisa foi realizada durante o mês de março de 2015 e utilizou como instrumento de coleta a entrevista estruturada que, conforme Severino (2007, p. 124), é "uma técnica de coleta de informações sobre um determinado assunto, diretamente solicitadas aos sujeitos pesquisados. Trata-se, portanto, de uma interação entre pesquisador e pesquisado."

Para melhor estruturação da análise dos dados obtidos, a pesquisa foi dividida entre as três categorias descritas acima, bem como também foram separados os dados de professores que lecionam disciplinas de formação geral e dos professores que lecionam disciplinas da área específica.

Dessa forma, os resultados que ora apresentaremos dedicam-se à avaliação dos dados relativos à categoria percepção de trabalho e trabalho docente, disponibilizados pelos professores que lecionam disciplinas da área de formação geral. Nosso método de análise está ancorado na discussão de análise de conteúdo de Bardin (2011, p.49), que "trabalha a fala, quer dizer, a prática da língua realizada por emissores identificáveis (...) tenta compreender os jogadores ou o ambiente do jogo num momento determinado, com o contributo das partes observáveis". Ou seja, compreender o quão é importante a contribuição dos entrevistados para a realização dessa pesquisa.

\section{PERCEPÇÃo de tRABalHO E tRABALHO DOCENTE: UMA ANÁlise dOS TRABALHADORES DA EDUCAÇÃO PROFISSIONAL}

Tomando como referência a categoria trabalho e trabalho docente, foco dessa análise, discutiremos os seguintes subgrupos: conceito de trabalho, diferenças do trabalho docente e outros tipos trabalho, especificidades da atuação do professor no âmbito da educação profissional e papel da educação profissional na formação dos sujeitos. 
A pesquisa foi realizada com seis docentes que lecionam disciplinas de formação geral em três instituições privadas de ensino profissional do município de Natal, de cursos distintos. Como metodologia para a análise, menciona-se a entrevista estruturada que foi gravada e transcrita. $\mathrm{O}$ roteiro foi estabelecido previamente e discutido na disciplina de Formação Docente e Práticas Pedagógicas para a Educação Profissional, com treze questões organizadas por eixos.

Considerando o objetivo da discussão do presente artigo apresenta-se como recorte a análise de duas questões acerca da categoria que trata sobre a percepção de trabalho e trabalho docente. E para tanto, foram realizados os seguintes questionamentos aos professores: Qual a sua concepção de trabalho? Existem diferenças entre trabalho docente e outros tipos de trabalho na sua percepção?

\subsection{Conceito de trabalho}

Refletindo sobre o conceito de trabalho, é possível perceber, nas falas dos professores, que a maioria dos entrevistados fez referência ao conceito de trabalho associado à atividade laborativa que exercem nas instituições aos quais estão vinculados, referendando situações que envolvem a relação com os alunos e o processo de ensino e aprendizagem, na perspectiva do trabalho como dom nato, "um sacerdócio, um ministério, alguma coisa que você se doa por amor." (PFG1, IE1, Curso 01). Referente ao conteúdo das entrevistas, podem ser destacados os seguintes resultados de acordo com a tabela a seguir:

\begin{tabular}{|l|l|}
\hline \multicolumn{2}{|c|}{ QUADRO 1 - PERCEPÇÃO SOBRE TRABALHO E TRABALHO DOCENTE } \\
\hline INSTITUIÇÃO- CURSO & PROFESSOR GERAL \\
\hline IE1- CURSO 1 & $\begin{array}{l}\text { PFG1: "eu vejo o meu trabalho como uma } \\
\text { troca de informações, eu não sou a ditadora } \\
\text { total do conteúdo que eu dou em sala de } \\
\text { aula, eu também aprendo muito com os } \\
\text { meus alunos. Eu acho que o trabalho em si } \\
\text { do professor é uma troca de informações." }\end{array}$ \\
& $\begin{array}{l}\text { PFG2: “o trabalho para mim é uma coisa } \\
\text { mais vocacionada. Para você ser professor, } \\
\text { tem que ter aquela vocação para exercer, } \\
\text { tem que ter aquele perfil. Para mim, é } \\
\text { como se fosse um sacerdócio, um } \\
\text { ministério, alguma coisa que você se doa } \\
\text { por amor. }\end{array}$ \\
\hline IE2-CURSO 2. & $\begin{array}{l}\text { PG1: "então o trabalho em si, a palavra } \\
\text { trabalho pra mim é isso é você fazer algo, } \\
\text { uma função em troca de algo financeiro, } \\
\text { então trabalho pra mim se resume a isso." }\end{array}$ \\
& $\begin{array}{l}\text { PG2: "Trabalho é a gente executar algo que } \\
\text { a gente aprendeu na teoria e consegue } \\
\text { associar na nossa prática(...). É uma }\end{array}$ \\
\hline
\end{tabular}




\begin{tabular}{|l|l|}
\hline & $\begin{array}{l}\text { responsabilidade que você tem que exercer } \\
\text { com segurança e também sempre } \\
\text { procurando dar o seu melhor" }\end{array}$ \\
\hline IE2- CURSO 3 & $\begin{array}{l}\text { PG1: “Trabalho é algo que me dignifica } \\
\text { como ser humano (...) O sentimento é de } \\
\text { você sentir-se útil. " }\end{array}$ \\
PG2: “A docência é gratificante porque é \\
uma troca de conhecimentos (...). Que seja \\
na assistência ou que seja na sala de aula há \\
uma preocupação da nossa parte em a cada \\
dia buscar esse conhecimento e aperfeiçoá- \\
lo"
\end{tabular}

Fonte: Quadro elaborado pelas autoras a partir das respostas dos entrevistados.

Nesse sentido, é relevante mencionar Freire (2011), quando afirma que o docente não é um profissional nato, mas ele se faz profissional, como quaisquer outros. E de acordo com a sua qualificação profissional será um bom ou mau docente, sendo, portanto, necessária não apenas a formação inicial, mas a continuidade dessa formação fundamentada no movimento histórico e dialético que perpassa a sociedade e, por conseguinte, a escola. E ainda acrescenta que (FREIRE, 2011, p. 39):

\footnotetext{
O saber que a prática docente espontânea ou quase espontânea, "desarmada", indiscutivelmente produz é um saber ingênuo, um saber de experiência feito, a que falta a rigorosidade metódica que caracteriza a curiosidade epistemológica do sujeito. [...]. Por isso é que, na formação permanente dos professores, o momento fundamental é o da reflexão crítica sobre a prática. É pensando criticamente a prática de hoje ou de ontem que se pode melhorar a próxima prática.
}

Numa outra direção, dois docentes, PFG2 (IE2 Curso 02) e PFG1 (IE2 Curso 02) fazem uma associação do trabalho à relação entre a teoria e prática ou a práxis. Nesse sentido, é relevante mencionar que a práxis proporciona a criação e a recriação na economia, arte e cultura e na sociedade em que o homem está inserido expressando uma resposta às suas necessidades que foram desenvolvidas no decorrer da história. (FRIGOTTO, 2012, p.30)

Apenas um dos entrevistados cita o trabalho como "uma troca financeira", ou seja, referencia à venda da força de trabalho em troca de um salário, o que faz alusão à construção do conceito de trabalho na perspectiva histórica, no âmbito das relações capitalistas de produção. A propósito desse aspecto, Frigotto (2012, p. 62) afirma que há no capitalismo:

[...] a divisão dos seres humanos entre aqueles que detêm a propriedade privada de capital (propriedade de meios e instrumentos de produção com o fim de gerar lucro) e aqueles que para se reproduzirem e manter suas vidas e a de seus filhos precisam ir ao mercado e vender sua força de trabalho, tendo em troca uma remuneração ou salário.

\subsection{Diferenças do trabalho docente e outros tipos trabalho}


Quando questionados sobre a existência de diferenças entre o trabalho docente e outros tipos de trabalhos, todos os entrevistados afirmaram que há, sim, diferenças. As justificativas mencionadas foram pelo fato de o professor ser o formador de opiniões, da ética profissional dos alunos, de lidar com pessoas, uma vez que influencia "muito na vida do aluno principalmente no curso profissionalizante" PFG1 (IE1, Curso 01), como também "ter que saber lidar com várias situações em uma única sala, porque tem pensamentos e ideias diferentes. " PFG2 (IE2, Curso $02)$.

O trabalho docente foi destacado pelos entrevistados como troca de informações e aprendizado com os alunos. Nesse sentido, destaca Pinto (2003) que o educador ingênuo não considera o aluno como sujeito e apenas a si próprio como único no ato pedagógico, dificultando o encontro das consciências. E, portanto, se faz necessário reconhecer o educando como sujeito para que esse possa colaborar junto ao docente e não sendo apenas passivo do processo educativo, pois ele não se sentirá como ignorante, mas como um possível educador, uma vez que começa a sua transformação.

Portanto, é relevante que diante da percepção do trabalho e trabalho docente seja feita a defesa da integração da formação básica e a profissional. Nessa perspectiva, Ramos (2005) destaca que a integração está além da associação da formação geral com a específica, pois exige ter como base trabalho, ciência e cultura. Dessa forma, pode-se desenhar o currículo integrado; deve-se problematizar os fenômenos; apresentar teorias e conceitos que contribuam para a apreensão do fenômeno estudado, localizando no campo da ciência visando a disciplinaridade e interdisciplinaridade; situar concepções de formação geral e específica tendo como fundamento a base científica, tecnológica, social cultural; organizar os componentes curriculares e as práticas pedagógicas.

\subsection{Especificidades da atuação do professor no âmbito da Educação Profissional}

No que tange ao questionamento acerca das especificidades para atuação do professor que leciona em instituições de educação profissional, surge de forma generalizada o entendimento que de fato elas existem, entretanto, as especificidades citadas direcionam o foco de atenção para caminhos distintos.

Exemplificado nas falas de três entrevistados: "levar o aluno o conhecimento específico para sua prática" PFG1 (IE2, Curso 02); "esteja apto a exercer uma profissão" PFG2 (IE1, Curso 01); "mostrar ao aluno como é esse caminho" PFG2 (IE2, Curso 02); é possível identificar que no entendimento destes, tais peculiaridades limitam-se à condição de capacitar o corpo discente para o exercício de uma profissão, para o mercado de trabalho, ou seja, uma atuação docente com foco direcionado a uma formação específica.

Numa outra linha de pensamento, são citadas como especificidades do docente a necessidade de conhecimentos na área técnica de formação, uma formação direcionada para a docência e a satisfação pessoal.

Com base nisto, identificamos que o corpo docente estudado ainda apresenta uma visão restrita do que é específico para a atuação docente no âmbito da educação profissional, visto que, recorrendo a Araújo (2008), para além do saber específico, perpassando a capacidade de 
instrumentalizar para o exercício de uma profissão, é também necessário a esses docentes ter o domínio dos saberes didáticos, de natureza científico-reflexiva; e saberes de pesquisador que viabilizem autonomia intelectual.

Ainda segundo Araújo (2008, p. 59), aos conhecimentos específicos devem ser incorporados aos saberes relativos ao "funcionamento da sociedade e das relações entre trabalho, cultura, ciência e Estado; ...às políticas públicas, sobretudo, as educacionais e de educação profissional; ....ao desenvolvimento local e às inovações".

\subsection{Papel da educação profissional na formação dos sujeitos}

Partindo do conteúdo das entrevistas, é possível perceber que a Educação Profissional é mencionada como uma formação para o mercado de trabalho que possa favorecer um retorno financeiro e que tem a função de colaborar para o conhecimento específico do aluno, ampliando sua visão acerca do curso técnico escolhido. E a especificidade da atuação do professor consiste na responsabilidade de expressar esse papel, "capacitando alguém que vai ser um profissional" PFG2 (IE2, Curso 01), destinados também "para aqueles que realmente estão buscando conhecimento a mais" PG1 (IE2, Curso 03). Para Gramsci (1982, p. 118):

Nessa escola não há espaço para a profissionalização. Assim, o autor critica a tendência italiana de "abolir qualquer tipo de escola "desinteressada" (não imediatamente interessada) e 'formativa', [...] bem como a de difundir cada vez mais as escolas profissionais especializadas, nas quais o destino do aluno e sua futura atividade são predeterminados"

Diante do exposto, entendemos que a escola deverá se desafiar e repensar o seu currículo na contramão dessa proposta pedagógica que prepara o sujeito exclusivamente com a competência técnica em detrimento da formação integral do sujeito.

No decorrer da pesquisa os entrevistados deixam claro que no seu processo formativo não foi discutida a Educação Profissional, ao afirmarem quando questionados sobre a ocorrência dessa discussão responderam: "Não. Até mesmo assim porque a disciplina que eu dou no curso profissionalizante ela é mais um complemento para os alunos". PFG1 (IE1, CE); "Sim. Rapaz, muito pouco ou quase nada. Eu diria até um não". PFG2 (IE2 Curso 02). Portanto, percebemos a ausência de uma proposta de Educação Profissional abancada nos princípios da formação humana integral a qual consiste em formar um cidadão não apenas para atuar no mercado de trabalho, mas que possibilite a travessia para uma sociedade mais justa e solidária.

Segundo MOURA (2014 p. 36):

[...] para atuar na perspectiva da transformação social, o professor deve ser, necessariamente, um intelectual que domine seu campo científico específico, os saberes inerentes ao ato de ensinar e tenha o comprometimento ético-político com a classe trabalhadora, à qual ele pertence.

Por conseguinte, entendemos que não basta ter apenas uma dessas características, mas o conjunto delas, em que pese o compromisso ético-político do docente, como via de acesso aos interesses sociais e coletivos da classe trabalhadora. 


\section{CONSIDERAÇÕES FINAIS}

Com base na revisão bibliográfica, bem como nos dados e resultados identificados na pesquisa realizada, compreendemos que os licenciados e bacharéis pesquisados dispõem de conhecimento sobre trabalho e trabalho docente, tendo em vista que identificam diferenças entre ambos. Porém, é relevante mencionar que essa visão não se baseia na criticidade que há nessa divisão entre os dois tipos de trabalho. Pois, não entendem o trabalho enquanto princípio educativo, mas, associando ao campo da Educação Profissional, como mero ensino voltado para a preparação, ou capacitação para o mercado de trabalho.

Nesse sentido, infere-se que há um desafio na formação docente de dotar esse trabalhador do ensino para que possa fazer uso de suas capacidades em sua plenitude e superar a barreira histórica construída na educação básica e profissional proporcionando uma formação humana integral nos cursos técnicos das instituições de ensino, para que não atendam apenas as demandas do mercado, ou em outras palavras, do sistema capitalista de produção.

De certo, viabilizar por meio da educação a emancipação dos sujeitos em que possam se situar a favor da hegemonia ou contra a hegemonia de forma consciente, compreendendo o movimento dialético e dialógico presente na sociedade de classes.

\section{REFERÊNCIAS}

1. ANTUNES, R. (2008). Século XXI: nova era da precarização estrutural do trabalho? In: Seminário Nacional de Saúde Mental e Trabalho, São Paulo. Recuperado em: http://www.fundacentro.gov.br/Arquivos/sis/EventoPortal/AnexoPalestraEvento/Mesa\%20 1\%20-\%20Ricardo\%20Antunes\%20texto.pdf

2. ARAÚJO, R. M. L. (2008). Formação de docentes para a educação profissional e tecnológica: por uma pedagogia integradora da educação profissional. In: Trabalho \& Educação, Belo Horizonte. Recuperado em: http://www.portal.fae.ufmg.br/seer/index.php/trabedu/article/viewFile/329/298.

3. BARDIN, L. (2011). Análise de Conteúdo. Tradução Luís Antero Reto, Augusto Pinheiro. São Paulo: Edições 70.

4. BRAVERMAN, H. (2011). Trabalho e Capital Monopolista: a degradação do trabalho no século $X X$ (3a ed.). Trad. de Nathanael C. Caixeiro.Rio de Janeiro: LTC.

5. FREIRE, P. (1974[2007]) Pedagogia do Oprimido (46a ed.). São Paulo: Paz e Terra.

6. _ (2011). Pedagogia da Autonomia: saberes necessários à pratica educativa. São Paulo: Paz e Terra.

7. FRIGOTTO, G., CIAVATTA, M. \& RAMOS, M., (2012). Concepções e mudanças no mundo do trabalho e o ensino médio. In: FRIGOTTO, Gaudêncio; Ensino Médio Integrado: concepções e contradições. São Paulo: Cortez.

8. GRAMSCl, A. (1982). Os intelectuais e a organização da cultura. 4. ed. Rio de Janeiro: Civilização Brasileira.

9. LIBÂNEO, J. C. (2001). Pedagogia e pedagogos: inquietações e buscas. Educar. Recuperado 
em: http://www.educaremrevista.ufpr.br/arquivos_17/libaneo.pdf

10. MARX, K. (1996). O capital: crítica da economia política. Livro 1 v. 1 . Tradução de Regis Barbosa e Flávio R. Kothe. São Paulo: Nova Cultural.

11. MARX, K., \& ENGELS, F. (1999). A Ideologia Alemã (11a ed.). São Paulo: Hucitec.

12. MÉSZÁROS, I. (2005). A educação para além do capital. Tradução de Isa Tavares. São Paulo: Boitempo.

13. MOURA, D. H., (org), (2013). Produção de conhecimento, políticas públicas e formação docente em educação profissional. - Campinas, SP: Mercado das Letras.

14. MOURA, D. H. (2014). Trabalho e formação docente na educação profissional [recurso eletrônico] / Dante Henrique Moura. - Dados eletrônicos (1 arquivo: 586 kilobytes). Curitiba: Instituto Federal do Paraná, - (Coleção formação pedagógica; v. 3).

15. PINTO, A. V. (2003). Sete Lições sobre Educação de Adultos. São Paulo: Cortez/Autores Associados.

16. PEREIRA, L. A. C. (2015). A formação de professores para a educação profissional. PROFISSIONAL, Fórum de Educação, 2004. Recuperado em: <http://portal.mec.gov.br/setec/arquivos/pdf/Texto_apresenta01.pdf>.

17. RAMOS, M. (2012). Possibilidades e desafios na organização do currículo integrado. In: FRIGOTTO, G, CIAVATTA, M. \& RAMOS, M. Ensino Médio Integrado: concepções e contradições. São Paulo: Cortez.

18. - (2010). Ensino médio integrado ciência, trabalho e cultura na relação entre educação profissional e básica. In: JAQUELINE MOLL \& Colaboradores. (Org.). Educação Profissional e tecnológica no Brasil contemporâneo: Desafios, tensões e possibilidades. Porto Alegre, RS: ARTMED.

19. SEVERINO, A. J., (2007). Metodologia do Trabalho Científico. São Paulo: Cortez. 